\title{
Nutrition, Calories
}

National Cancer Institute

\section{Source}

National Cancer Institute. Nutrition, Calories. NCI Thesaurus. Code C15646.

Role of caloric intake in cancer causation or prevention and in general health. 